\title{
Dinâmica Populacional Aplicada à Conservação de Alimentos: Interação entre Listeria Monocytogenes e Bactérias Lácticas ${ }^{1}$
}

R.R. DELBONI ${ }^{2}$, H.M. YANG ${ }^{3}$, Departamento de Matemática Aplicada, IMECC, UNICAMP e Lab-Epifisma, Cx.P. 6065, 13083-859 Campinas, SP, Brasil.

\begin{abstract}
Resumo. Neste trabalho, foi desenvolvido um modelo matemático que visa descrever as interações entre bactérias lácticas produtoras de bacteriocinas e a Listeria monocytogenes no alimento. As bactérias lácticas produzem bacteriocinas que preservam alimentos por meio de exclusão competitiva com outros microorganismos nocivos, como a Listeria. A análise estática e a dinâmica do modelo, representado por um sistema de equações diferenciais ordinárias, fornecem informações sobre o comportamento das soluções, e, também, permitem estudar a possível ação do ácido láctico e da bacteriocina, produzidos pela bactéria láctica, na redução e inibição de atividade de Listeria no alimento.
\end{abstract}

\section{Introdução}

Com o aumento do consumo de produtos refrigerados, a Listeria monocytogenes tornou-se um dos mais importantes patógenos veiculados por alimentos na década de 80, devido a diversos surtos de listeriose humana, epidemiologicamente ligados a alimentos. Listeria monocytogenes é uma bactéria patogênica que está amplamente distribuída na natureza, podendo ser encontrada em plantas processadoras de alimentos, nas mãos de manipuladores e na forma de biofilme aderido aos equipamentos [6]. Este microorganismo pode sobreviver numa faixa de temperatura de $1 \mathrm{a} 45^{\circ} \mathrm{C}$, tornando-se um risco para segurança de alimentos refrigerados [5].

Listeriose é o nome de um grupo geral de desordens causada pela L. monocytogenes, e que tem a maior taxa de mortalidade dentre as infecções de origem alimentar. Além disso, a contaminação de alimentos pela $L$. monocytogenes pode acarretar perdas econômicas substanciais aos produtores de alimentos. Os surtos de listeriose têm sido associados com alimentos tais como: leite cru e leite pasteurizado, queijos (particularmente frescais), sorvetes, salsichas e linguiças fermentadas (cruas), carne crua (todos os tipos), frango cozido ou cru e defumado. A síndrome clínica associada à listeriose é semelhante à causada pelo vírus influenza, podendo evoluir para

\footnotetext{
${ }^{1}$ Apoio financeiro FAPESP (Projeto Temático)

${ }^{2}$ Bolsista FAPESP (rodelboni@ime.unicamp.br)

${ }^{3}$ Bolsista CNPq (hyunyang@ime.unicamp.br)
} 
meningo-encefalite, septicemia e endocardite, podendo ainda causar aborto e outras complicações em mulheres grávidas [7].

Bactérias lácticas é uma nomenclatura genérica utilizada para designar um grupo constituído por bactérias Gram-positivas com características morfológicas, metabólicas e fisiológicas semelhantes, que produzem ácido láctico como produto final do metabolismo de carboidratos. As condições ácidas do meio melhoram a competitividade das bactérias lácticas que apresentam maior tolerância ao pH baixo extra e intracelular. As bactérias lácticas são capazes de preservar alimentos por meio da exclusão competitiva com outros microorganismos e também através da produção de substâncias inibitórias, incluindo-se as bacteriocinas.

Além de inibir o crescimento de patógenos nos alimentos fermentados, tais como leite fermentado, iogurte, bebidas e salame, as bactérias lácticas podem proporcionar efeitos benéficos à saúde. Esses alimentos contendo bactérias promotoras de benefícios à saúde são denominados alimentos probióticos. O efeito de conservação atribuído às bactérias lácticas, no processamento e estocagem de produtos fermentados deve-se principalmente à rápida produção de ácido láctico. Em sua forma dissociada, o ácido láctico atravessa passivamente a membrana citoplasmática, acidificando o meio intracelular a tal ponto que as funções celulares são inibidas e o potencial de membrana anulado. De acordo com os regulamentos da FDA ("Food and Drug Administration"), antimicrobianos naturais usados como conservantes de alimentos tem que ser produzidos por microorganismos GRAS ("Generally Recognized as Safe"). Como muitas espécies de bactérias lácticas tem o status GRAS, essas têm sido extensamente estudadas para a produção de bacteriocinas. Além da inibição de L. monocytogenes, as bacteriocinas de bactérias lácticas podem inibir a multiplicação de outros microorganismos como Bacillus cereus, Staphylococcus aureus e Clostridium botulinum.

Uma definição recente sobre bacteriocinas produzidas por bactérias lácticas sugere que estes compostos devem ser considerados como produtos primários extracelulares, sintetizados no ribossoma bacteriano, os quais podem apresentar um espectro de atividade limitado [2]. Uma grande vantagem da utilização de bacteriocinas como conservador de alimentos está relacionada com a segurança garantida aos consumidores, visto que as bactérias lácticas e seus metabólitos, dentre os quais as bacteriocinas, têm sido consumidas nos alimentos fermentados há muito tempo sem causar efeitos nocivos à saúde.

A ação bactericida das bacteriocinas ocorre por meio da desestabilização funcional da membrana citoplasmática, causada provavelmente por sua ação detergente. Segundo Desmazeaud [3], a biossíntese das bacteriocinas é realizada no final da fase exponencial de crescimento bacteriano. A tecnologia dos obstáculos combina diversos métodos de preservação inibitórios ao crescimento microbiano. As bacteriocinas podem atuar em sinergia com outros tratamentos, contribuindo para a melhoria da segurança do alimento [1].

Neste trabalho desenvolve-se um modelo matemático que descreve as interações entre bactérias lácticas produtoras de bacteriocinas e a Listeria no alimento. O modelo pressupõe a capacidade de suporte do meio (alimento) como fator limitante do crescimento da bactéria láctica. É considerada também a perda de estabilidade do ácido láctico e da bacteriocina no decorrer do tempo. Da análise do modelo 
obtém-se informações sobre o comportamento das soluções, e também analisa-se a possível ação do ácido láctico e da bacteriocina, produzidos pela bactéria láctica, para o controle da Listeria no alimento.

\section{Modelo Matemático}

Faz-se uma modelagem matemática do fenômeno biológico de interação da bactéria láctica e da Listeria monocytogenes. Denota-se por $P$ e $L$ as populações, respectivamente, de bactérias lácticas e de Listeria num dado instante $t$. As quantidades de ácido láctico e de bacteriocina produzidos pela bactéria láctica são representadas por $A$ e $B$, respectivamente. O modelo é descrito por um sistema de equações diferenciais ordinárias não lineares dado por

$$
\left\{\begin{array}{l}
\frac{d P}{d t}=P \phi_{1}\left(1-\frac{P}{k}\right)-\mu_{1} P \\
\frac{d A}{d t}=\alpha_{1} \phi_{1} P-\mu_{2} A-\delta_{1} A L \\
\frac{d B}{d t}=\alpha_{2} \phi_{1} P-\mu_{3} B-\delta_{2} B L \\
\frac{d L}{d t}=\phi_{2} L-\mu_{4} L-\delta_{1} A L-\delta_{2} B L,
\end{array}\right.
$$

onde $P \geq 0, A \geq 0, B \geq 0, L \geq 0$ e cujos parâmetros são constantes positivas definidos a seguir. A Figura 1 mostra um esquema da dinâmica populacional das bactérias utilizando os compartimentos do sistema de equações diferenciais ordinárias (2.1). $\phi_{1}$ e $\mu_{1}$ são taxas intrínseca de crescimento e de mortalidade das bactérias lácticas; $\alpha_{1} \phi_{1}$ é a taxa de produção per-capita de ácido láctico pelas bactérias lácticas, com $\alpha_{1}$ sendo um fator de produção de ácido láctico durante a proliferação de bactérias lácticas; $\alpha_{2} \phi_{1}$ é a taxa de produção per-capita de bacteriocina pelas bactérias lácticas, com $\alpha_{2}$ sendo um fator de produção de bacteriocina durante a proliferação de bactérias lácticas; $\mu_{2}$ e $\mu_{3}$ são as taxas de perda de estabilidade do ácido láctico e da bacteriocina; e $\phi_{2}$ e $\mu_{4}$ são as taxas per-capita de crescimento e de mortalidade da Listeria. O modelo inclui um fator limitante para o crescimento natural das bactérias lácticas representado pelo parâmetro $k$, ou seja, o crescimento da população é limitado pela capacidade de suporte do meio (representado pelo alimento). Assim, observa-se que a taxa de crescimento per-capita da bactéria láctica $\phi_{P}=\left(\phi_{1}-\phi_{1} P / k\right)$ decresce linearmente com a população, ou seja, a população cresce assintoticamente para um determinado nível sustentável pelo meio devido a limitação de nutrientes disponíveis.

Tanto ácido láctico quanto bacteriocina são metabólitos produzidos durante o processo de multiplicação de bactérias lácticas, porém simplificamos assumindo a sua produção proporcional somente com a taxa intrínseca de crescimento.

É assumido que a interação tende a inibir o crescimento da população de Listeria e diminuir a concentração do metabólito envolvido na interação. Os parâmetros $\delta_{1}$ e $\delta_{2}$ correspondem, respectivamente, às taxas de interação da Listeria com o ácido láctico e com a bacteriocina. Dessa maneira, a população de Listeria sofre uma redução de $\delta_{1} A L$ e $\delta_{2} B L$ quando ocorrem interações com o ácido láctico e a bacteriocina, respectivamente. A ação desses metabólitos produzidos pelas bactérias 


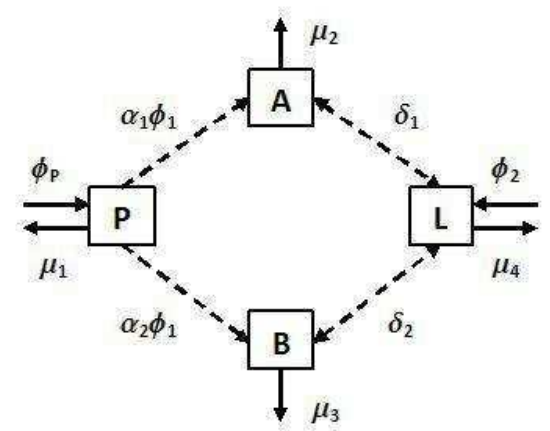

Figura 1: Esquema da dinâmica populacional das bactérias utilizando os compartimentos do sistema de equações diferenciais ordinárias (2.1). As flexas pontilhadas unidirecionais indicam a produção por bactérias lácticas, enquanto flechas bidirecionais, indicam o consumo pela ligação com Listeria.

lácticas ocorre sobre a membrana citoplasmática da Listeria. Assim, assumimos que, tanto o ácido láctico quanto a bacteriocina são "consumidos" à medida que interagem com a Listeria, e portanto, as concentrações de ácido láctico e de bacteriocina diminuem em $\delta_{1} A L$ e $\delta_{2} B L$, respectivamente, em cada instante de tempo quando ocorrem as interações. Outra simplificação é assumir que a capacidade de suporte seja ilimitada para Listeria.

\section{Análise do Modelo}

Para analisar o modelo, vamos, inicialmente, estudar esse sistema dinâmico em regime estacionário.

\subsection{Pontos de equilíbrio}

O sistema de equações (2.1) tem três pontos de equilíbrio.

Ausência de microorganismos, $Q_{1}$. Se $\phi_{1}<\mu_{1}$, obtém-se apenas um ponto de equilíbrio correspondente à solução trivial $Q_{1}=\left(P_{1}, A_{1}, B_{1}, L_{1}\right)=(0,0,0,0)$.

Ausência de Listeria, $Q_{2}$. Se $\phi_{1}>\mu_{1}$, obtém-se o segundo ponto de equilíbrio que corresponde a $Q_{2}=\left(P_{2}, A_{2}, B_{2}, L_{2}\right)=\left(\left(\frac{\phi_{1}-\mu_{1}}{\phi_{1}}\right) k, \frac{\alpha_{1}\left(\phi_{1}-\mu_{1}\right)}{\mu_{2}} k, \frac{\alpha_{2}\left(\phi_{1}-\mu_{1}\right)}{\mu_{3}} k, 0\right)$.

Listeria interagindo com bactéria láctica, $Q_{3}$. Se $\phi_{2}-\mu_{4}-\delta_{1} A-\delta_{2} B=0$, o terceiro ponto de equilíbrio é dado por $Q_{3}=\left(P_{3}, A_{3}, B_{3}, L_{3}\right)$, onde as três primeiras coordenadas, em função de $L_{3}$, são dadas por

$$
P_{3}=\left(\frac{\phi_{1}-\mu_{1}}{\phi_{1}}\right) k, \quad A_{3}=\frac{\alpha_{1}\left(\phi_{1}-\mu_{1}\right)}{\mu_{2}+\delta_{1} L_{3}} k, \quad B_{3}=\frac{\alpha_{2}\left(\phi_{1}-\mu_{1}\right)}{\mu_{3}+\delta_{2} L_{3}} k .
$$

Substituindo na quarta equação do sistema (2.1) em estado estacionário, os valores de $A$ e $B$ por $A_{3}$ e $B_{3}$, respectivamente, obtém-se a equação de segundo 
grau

$$
a_{2} L_{3}^{2}+a_{1} L_{3}+a_{0}=0
$$

cuja solução corresponde a última coordenada $L_{3}$, e onde os coeficientes, com $\phi_{1}>$ $\mu_{1}$, são

$$
\begin{aligned}
& a_{2}=\left(\phi_{2}-\mu_{4}\right) \delta_{1} \delta_{2} \\
& a_{1}=\left(\phi_{2}-\mu_{4}\right)\left[\mu_{2} \delta_{2}+\mu_{3} \delta_{1}-\frac{\delta_{1} \delta_{2} k\left(\phi_{1}-\mu_{1}\right)\left(\alpha_{1}+\alpha_{2}\right)}{\phi_{2}-\mu_{4}}\right] \\
& a_{0}=\left(\phi_{2}-\mu_{4}\right)\left[\mu_{2} \mu_{3}-\frac{k\left(\phi_{1}-\mu_{1}\right)\left(\alpha_{1} \delta_{1} \mu_{3}+\alpha_{2} \delta_{2} \mu_{2}\right)}{\phi_{2}-\mu_{4}}\right] .
\end{aligned}
$$

Os pontos de equilíbrio $Q_{2}$ e $Q_{3}$ têm os mesmos valores para bactérias lácticas, $P_{2}=P_{3}$, pois a sua dinâmica não é influenciada por outras variáveis. Num trabalho futuro introduziremos a inibição de ácido láctico na atividade produtiva de bactérias lácticas, também. As concentrações de ácido láctico e bacteriocina ficam diminuídas em relação ao equilíbrio anterior.

Analisa-se a existência do ponto de equilíbrio $Q_{3}$. Primeiro, para $\phi_{2}<\mu_{4}$, observa-se que os coeficientes $a_{2}<0, a_{1}<0$ e $a_{0}<0$ e, portanto, o polinômio (3.1) não possui raiz real positiva. Nesse caso, tem-se o equilíbrio $Q_{1}$, se $\phi_{1}<\mu_{1}$, ou $Q_{2}$, se $\phi_{1}>\mu_{1}$.

Entretanto, se $\phi_{2}>\mu_{4}$, o coeficiente $a_{2}$ é positivo, mas $a_{1}$ e $a_{0}$ dependem do sinal do termo entre colchetes. Para o coeficiente $a_{1}$, o termo entre colchetes fica

$$
\begin{gathered}
{\left[\mu_{2} \delta_{2}+\mu_{3} \delta_{1}-\frac{\delta_{1} \delta_{2} k\left(\phi_{1}-\mu_{1}\right)\left(\alpha_{1}+\alpha_{2}\right)}{\phi_{2}-\mu_{4}}\right]>0 \Leftrightarrow} \\
\delta_{2}\left[\frac{\delta_{1} k\left(\phi_{1}-\mu_{1}\right)\left(\alpha_{1}+\alpha_{2}\right)}{\phi_{2}-\mu_{4}}-\mu_{2}\right]<\mu_{3} \delta_{1} \Leftrightarrow \delta_{2}<\frac{\mu_{3} \delta_{1}}{\bar{k} \delta_{1}-\mu_{2}},
\end{gathered}
$$

onde

$$
\bar{k}=\frac{k\left(\phi_{1}-\mu_{1}\right)\left(\alpha_{1}+\alpha_{2}\right)}{\phi_{2}-\mu_{4}} .
$$

Para o coeficiente $a_{0}$, tem-se, para o termo entre colchetes,

$$
\begin{gathered}
{\left[\mu_{2} \mu_{3}-\frac{k\left(\phi_{1}-\mu_{1}\right)\left(\alpha_{1} \delta_{1} \mu_{3}+\alpha_{2} \delta_{2} \mu_{2}\right)}{\phi_{2}-\mu_{4}}\right]>0 \quad \Leftrightarrow} \\
k\left(\phi_{1}-\mu_{1}\right)\left(\alpha_{1} \delta_{1} \mu_{3}+\alpha_{2} \delta_{2} \mu_{2}\right)<\mu_{2} \mu_{3}\left(\phi_{2}-\mu_{4}\right) \quad \Leftrightarrow \quad \delta_{2}<c-d \delta_{1},
\end{gathered}
$$

onde

$$
c=\frac{\mu_{3}\left(\phi_{2}-\mu_{4}\right)}{k\left(\phi_{1}-\mu_{1}\right) \alpha_{2}} \quad \text { e } \quad d=\frac{\alpha_{1} \mu_{3}}{\alpha_{2} \mu_{2}} .
$$

Resumindo, para $\phi_{2}>\mu_{4}$ : (1) $a_{2}>0$ (sempre); (2) $a_{1}>0 \Leftrightarrow \delta_{2}<\mu_{3} \delta_{1}\left(\bar{k} \delta_{1}-\right.$ $\left.\mu_{2}\right)^{-1}$; e $(3) a_{0}>0 \Leftrightarrow \delta_{2}<c-d \delta_{1}$. Do gráfico de $\delta_{2}$ em função de $\delta_{1}$, da reta $\delta_{2}=c-d \delta_{1}$ e da hipérbole $\delta_{2}=\mu_{3} \delta_{1}\left(\bar{k} \delta_{1}-\mu_{2}\right)^{-1}$, estudando a variação dos sinais dos coeficientes do polinômio 3.1, obtém-se regiões nas quais é possível obter apenas uma única raiz real positiva para o polinômio. As curvas de $\delta_{2}$ em função de $\delta_{1}$ são mostradas na Figura 2. Observa-se que, para a existência de uma raiz real positiva para o polinômio (3.1), é suficiente que satisfaça $\delta_{2}>c-d \delta_{1}$. Assim, na região 


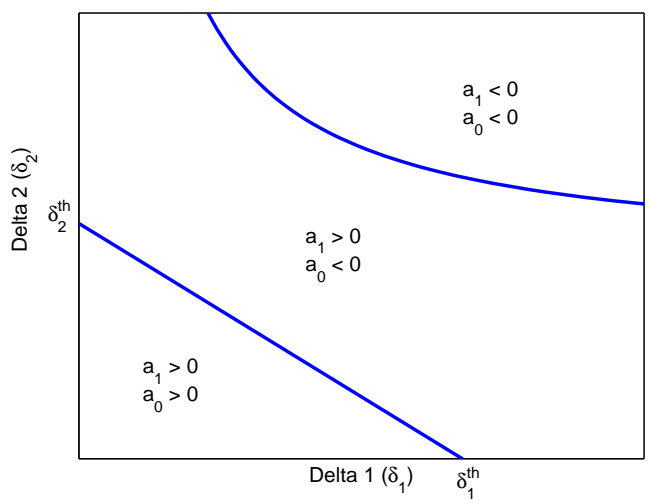

Figura 2: Regiões com sinais dos coeficientes $a_{0}$ e $a_{1}$ do polinômio (3.1), com $a_{2}>0$.

acima da reta $\delta_{2}=c-d \delta_{1}$ o terceiro ponto de equilíbrio dado por $\left(P_{3}, A_{3}, B_{3}, L_{3}\right)$ existe. Nota-se também que quanto maior for o valor de $c$, maior será o risco de contaminação do alimento pela Listeria monocytogenes.

Como $c=\frac{\phi_{2}-\mu_{4}}{B_{2}}$, é a taxa de produção líquida de Listeria dividido pela quantidade de bacteriocina no equilíbrio, o parâmetro $c$ mede o risco de infestação de Listeria na presença da bacteriocina no alimento. E, como $d=\left(\frac{\alpha_{1} \phi_{1}}{\mu_{2}}\right) /\left(\frac{\alpha_{2} \phi_{1}}{\mu_{3}}\right)$, é a quantidade per-capita de ácido láctico produzida durante tempo de ação do ácido láctico dividido pela quantidade per-capita de bacteriocina produzida durante tempo de ação da bacteriocina, o parâmetro $d$ mede a produção relativa, por parte de bactérias láticas, entre ácido lático e bacteriocina. Portanto mede a especialização de determinada bactéria na produção de ácido lático em detrimento de bacteriocina.

\subsection{Estabilidade dos pontos de equilíbrio}

A estabilidade local dos pontos de equilíbrio é determinada pelos autovalores da matriz jacobiana do sistema (2.1), obtidos de $\Psi(\lambda)=\operatorname{det}(J-\lambda I)=0$, onde det é o determinante de uma matriz e $I$ é a matriz identidade. A linearização desse sistema resulta em

$$
J=\left[\begin{array}{cccc}
\left(\phi_{1}-\mu_{1}\right)-2 \phi_{1} \frac{P}{k} & 0 & 0 & 0 \\
\alpha_{1} \phi_{1} & -\mu_{2}-\delta_{1} L & 0 & -\delta_{1} A \\
\alpha_{2} \phi_{1} & 0 & -\mu_{3}-\delta_{2} L & -\delta_{2} B \\
0 & -\delta_{1} L & -\delta_{2} L & \left(\phi_{2}-\mu_{4}-\delta_{1} A-\delta_{2} B\right)
\end{array}\right]
$$

Se a parte real de todos os autovalores for negativa, então o ponto de equilíbrio é estável [4]. 
Para o ponto de equilíbrio trivial $Q_{1}$, a matriz jacobiana é

$$
J_{0}=\left[\begin{array}{cccc}
\left(\phi_{1}-\mu_{1}\right) & 0 & 0 & 0 \\
\alpha_{1} \phi_{1} & -\mu_{2} & 0 & 0 \\
\alpha_{2} \phi_{1} & 0 & -\mu_{3} & 0 \\
0 & 0 & 0 & \left(\phi_{2}-\mu_{4}\right)
\end{array}\right],
$$

cujos autovalores são: $\lambda_{1}=\phi_{1}-\mu_{1}, \lambda_{2}=-\mu_{2}, \lambda_{3}=-\mu_{3}$ e $\lambda_{4}=\phi_{2}-\mu_{4}$. O primeiro e o último autovalores serão negativos se $\phi_{1}<\mu_{1}$ e $\phi_{2}<\mu_{4}$, respectivamente. Portanto, o ponto de equilíbrio $Q_{1}$ é localmente assintoticamente estável para $\phi_{1}<$ $\mu_{1}$ e $\phi_{2}<\mu_{4}$.

Para o ponto de equilíbrio $Q_{2}$, a matriz jacobiana é

$$
J_{2}=\left[\begin{array}{cccc}
\left(\mu_{1}-\phi_{1}\right) & 0 & 0 & 0 \\
\alpha_{1} \phi_{1} & -\mu_{2} & 0 & \frac{-\delta_{1} \alpha_{1}\left(\phi_{1}-\mu_{1}\right) k}{\mu_{2}} \\
\alpha_{2} \phi_{1} & 0 & -\mu_{3} & \frac{-\delta_{2} \alpha_{2}\left(\phi_{1}-\mu_{1}\right) k}{\mu_{3}} \\
0 & 0 & 0 & \left(\phi_{2}-\mu_{4}\right)-\left(\phi_{1}-\mu_{1}\right) k\left[\frac{\delta_{1} \alpha_{1}}{\mu_{2}}+\frac{\delta_{2} \alpha_{2}}{\mu_{3}}\right]
\end{array}\right],
$$

cujos três autovalores são: $\lambda_{1}=\mu_{1}-\phi_{1}, \lambda_{2}=-\mu_{2}$ e $\lambda_{3}=-\mu_{3}$, que são todos negativos para $\phi_{1}>\mu_{1}$. O último é $\lambda_{4}$, dado por

$$
\lambda_{4}=\left(\phi_{2}-\mu_{4}\right)-\left(\phi_{1}-\mu_{1}\right) k\left(\frac{\delta_{1} \alpha_{1}}{\mu_{2}}+\frac{\delta_{2} \alpha_{2}}{\mu_{3}}\right),
$$

que é negativo se $\delta_{2}>c-d \delta_{1}$. Quando a Listeria não se reproduz eficientemente, ou seja, $\phi_{2}<\mu_{4}$, então para qualquer valor de $\delta_{2}\left(\operatorname{com} \phi_{1}>\mu_{1}\right)$ não há necessidade de bactéria láctica para controlá-la, pois não consegue se estabelecer. Porém, se a Listeria se reproduz eficientemente, ou seja, $\phi_{2}>\mu_{4}$, então o ponto de equilíbrio $Q_{2}$ será estável se, e somente se, $\delta_{2}>c-d \delta_{1}$, ou seja, as bactérias lácticas devem ter intensa atividade. Isso significa que, se a taxa de produção líquida de Listeria em relação à quantidade de bacteriocina (representada por $c$ ) for muito alta, então a ação inibidora do ácido láctico, representada pelo parâmetro $\delta_{1}$ também deve ser elevada. Também é possível controlar a contaminação pela Listeria se a ação inibidora da bacteriocina (representada por $\delta_{2}$ ) for intensa (Figura 3a).

Resume-se as regiões de estabilidade, levando-se em conta $Q_{1}$ e $Q_{2}$ : para $\phi_{1}<\mu_{1}$ e $\phi_{2}<\mu_{4}, Q_{1}$ é estável; e para $\phi_{1}>\mu_{1}$ e $\phi_{2}<\mu_{4}, Q_{2}$ é estável. Agora, para $\phi_{1}>\mu_{1}$ e $\phi_{2}>\mu_{4}, Q_{2}$ continua estável para $\delta_{2}>c-d \delta_{1}$; caso contrário, instável. Essas três últimas condições são também necessárias para a existência do equilíbrio $Q_{3}$, com $\left(P_{3}, A_{3}, B_{3}, L_{3}\right)$. Logo, na região onde $Q_{2}$ é instável, também não existe $Q_{3}$, e $Q_{1}$ é instável. Será discutido a seguir, a estabilidade do ponto de equilíbrio $Q_{3}$, assim como a natureza do ponto de equilíbrio atrator na região onde $Q_{3}$ não existe.

Uma das equações para se obter o ponto de equilíbrio $Q_{3}$ é $\phi_{2}-\mu_{4}-\delta_{1} A-\delta_{2} B=$ 0 , que é satisfeita, também, se substituir os valores em equilíbrio de $A_{2}$ e $B_{2}$ do ponto $Q_{2}$. Por isso estuda-se a quarta equação do sistema (2.1) em torno do ponto de equilíbrio $Q_{2}$, isto é, supondo regime quase estacionário para as variáveis $A$ e $B$. Assim, impondo $A=A_{2}$ e $B=B_{2}$, a solução para essa equação é dada por

$$
L(t)=L_{0} e^{\left(\phi_{2}-\mu_{4}-\delta_{1} A_{2}-\delta_{2} B_{2}\right) t},
$$


onde em $t=0$ tem-se $L(0)=L_{0}$, que é um problema de valor inicial. Note que, quando a taxa de replicação de Listeria é baixa, com $\phi_{2}<\mu_{4}$, então, independente de valores dados para $\delta_{1}$ e $\delta_{2}$, a concentração de Listeria tende para zero para todos os valores iniciais $L_{0}$, pois o expoente de (3.3) é negativo. Logo, para $\phi_{2}<\mu_{4}$, o sistema (2.1) tende para o equilíbrio $Q_{2}$, pois $\phi_{1}>\mu_{1}$.

Quando, porém, a taxa de replicação da Listeria é elevada, com $\phi_{2}>\mu_{4}$, existem dois comportamentos dinâmicos distintos. Quando a interação do ácido láctico e da bacteriocina com a Listeria é próximo de zero, ou seja, $\delta_{1} \rightarrow 0$ e $\delta_{2} \rightarrow 0$, o expoente da equação (3.3) é aproximadamente $\left(\phi_{2}-\mu_{4}\right) t$, valor positivo. O mesmo vale para interação fraca, ou seja, quando $\delta_{2}<c-d \delta_{1}$. Logo, quando os únicos fatores que poderiam inibir e controlar o crescimento da Listeria, o ácido láctico e a bacteriocina, atuam fracamente, nessa situação tem-se $L \rightarrow \infty$ quando $t \rightarrow \infty$, ou seja, a população de Listeria cresce indefinidamente, por não existir praticamente nenhum controle, nem tampouco limitação de recursos. Contudo, nessa região de interação fraca, dada por $\delta_{2}<c-d \delta_{1}$, os pontos de equilíbrio $Q_{1}$ e $Q_{2}$ são instáveis, e $Q_{3}$ não está definido. Portanto, o sistema dinâmico (2.1), quando $t \rightarrow \infty$, tende para $L \rightarrow \infty, A \rightarrow 0, B \rightarrow 0$ e $P \rightarrow P_{2}$. Quando se tem exatamente $\delta_{2}=c-d \delta_{1}$, a fronteira para deixar de existir $Q_{3}$, o expoente de (3.3), com valores de equilíbrio de $Q_{2}$, é zero. Agora, no outro extremo, quando $\delta_{1} \rightarrow \infty$ e $\delta_{2} \rightarrow \infty$, o expoente de (3.3) é tal que $\left(\phi_{2}-\mu_{4}-\delta_{1} A_{2}-\delta_{2} B_{2}\right) \rightarrow-\infty$. Assim, para todo $t$, em especial quando $t \rightarrow \infty$, tem-se $L \rightarrow 0$. O mesmo comportamento é válido para interação forte, ou seja, $\delta_{2}>c-d \delta_{1}$, onde o ponto de equilíbrio $Q_{2}$ é estável. Assim, nessa região todas as trajetórias do sistema dinâmico aproximam dos valores de equilíbrio dados por $Q_{2}$.

Conclui-se, assim, que o ponto de equilíbrio $Q_{3}$ é instável. Qualquer perturbação nas coordenadas desse equilíbrio levará o sistema (2.1) dinâmico ou para as coordenadas do equilíbrio $Q_{2}\left(\delta_{2}>c-d \delta_{1}\right)$, ou fará a Listeria crescer indefinidamente $\left(\delta_{2}<c-d \delta_{1}\right)$.

Figura 2 mostra que é possível obter os valores limiares, designados por $\delta_{1}^{t h} \mathrm{e}$ $\delta_{2}^{\text {th }}$, para que $Q_{2}=\left(P_{2}, A_{2}, B_{2}, 0\right)$ seja estável em função de apenas um parâmetro. Esses valores limiares são obtidos quando $\delta_{1}$ e $\delta_{2}$ forem maiores do que os valores que a reta $\delta_{2}=c-d \delta_{1}$ intercepta o eixo- $x$ ou o eixo- $y$, respectivamente. Assim basta que $\delta_{2}>\delta_{2}^{t h}=c$ para que $Q_{2}$ seja estável independente de $\delta_{1}$. O mesmo vale para $\delta_{1}>\delta_{1}^{t h}=\frac{c}{d}$, para não depender de $\delta_{2}$. Esses valores limiares têm uma aplicação prática muito importante. Quando a bacteriocina é bastante reativa com a Listeria, cuja interação situa-se acima do seu valor limiar, ou seja, $\delta_{2}>\delta_{2}^{t h}$, então, independente do valor de $\delta_{1}$, é possível controlar o crescimento da Listeria, pois nessa região o ponto de equilíbrio $Q_{2}$ é estável, onde $L_{2}=0$. Esse fato é bastante interessante, visto que a crescente acidez, sempre causada pelo excesso de ácido láctico, não é desejável em alguns alimentos como a carne, por exemplo, porque pode causar características organolépticas indesejáveis ao alimento. Ressalta-se que a presença de bacteriocina no alimento não causa características indesejáveis, como sabor estranho, por isso um tipo de bacteriocina (nisina) já foi aprovado e é utilizado na forma purificada como conservante em alguns alimentos. Esta prática é uma forma de controle preconizada pelo modelo proposto. Como o parâmetro $c$ mede o risco de infestação de Listeria na presença da bacteriocina no alimento, é 
justificada a eliminação de Listeria quando $\delta_{2}>\delta_{2}^{t h}$. Porém, $\frac{c}{d}=\frac{\mu_{2}\left(\phi_{2}-\mu_{4}\right)}{k\left(\phi_{1}-\mu_{1}\right) \alpha_{1}}$ é a taxa de produção líquida de Listeria dividido pela quantidade de ácido láctico no equilíbrio, e assim, o parâmetro $\frac{c}{d}$ mede o risco de infestação de Listeria na presença do ácido láctico no alimento. Por isso o resultado $\delta_{1}>\delta_{1}^{t h}$.

Figura 3 mostra simulações numéricas do modelo, com valores dos parâmetros arbitrários para se ter $\phi_{1}>\mu_{1}, \phi_{2}>\mu_{4}$ e $\delta_{2}<c-d \delta_{1}$. Na Figura 3b, as trajetórias dinâmicas são atraídas para $P \rightarrow P_{2}, A \rightarrow 0, B \rightarrow 0$ e $L \rightarrow \infty$, que não é um ponto de equilíbrio. Quando a última desigualdade é trocada $\left(\delta_{2}>c-d \delta_{1}\right)$, mas mantidas as duas primeiras, as trajetórias tendem para o ponto de equilíbrio $\left(P_{2}, A_{2}, B_{2}, 0\right)$ (Figura 3a).
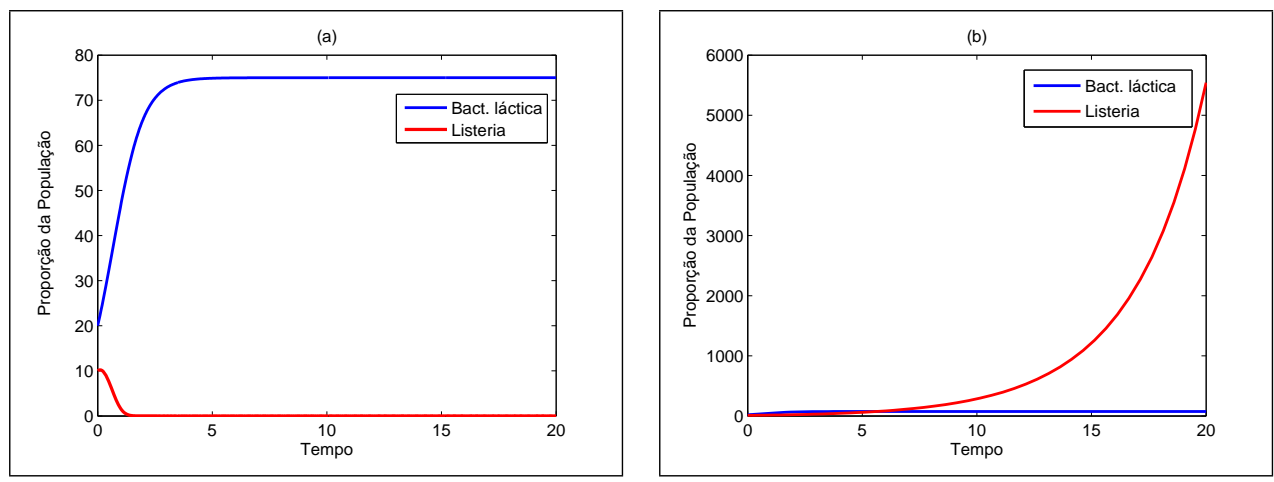

Figura 3: Interação entre bactéria láctica e Listeria. Em (a), Listeria é controlada pela bacteriocina, pois os parâmetros $\delta_{1}=0,01$ e $\delta_{2}=0,04$ estão acima da reta $\delta_{2}=c-d \delta_{1}$ e assim, o ponto $Q_{2}$ é estável. Em (b), $\delta_{1}=0,00005$ e $\delta_{2}=0,00007$ estão abaixo da reta $\delta_{2}=c-d \delta_{1}$, caso em que o ponto $Q_{2}$ é instável. Nessa situação, as concentrações de ácido láctico e bacteriocina tendem para zero devido ao aumento de Listeria $(L \rightarrow \infty)$, mas a população de bactérias lácticas tende para $P_{2}$. Os valores dos parâmetros utilizados são $k=100, \phi_{1}=2, \phi_{2}=1, \alpha_{1}=1, \alpha_{2}=2, \mu_{1}=0,5, \mu_{2}=0,1, \mu_{3}=0,3$ e $\mu_{4}=0,6$.

\section{Conclusão}

Neste trabalho, desenvolveu-se um modelo matemático simples para descrever a interação entre bactérias lácticas produtoras de bacteriocinas e a Listeria no alimento. O modelo pressupõe a capacidade de suporte do meio como fator limitante apenas para o crescimento da bactéria láctica, assim como a perda de estabilidade do ácido láctico e da bacteriocina produzidos pelas bactérias. O modelo exibe três pontos de equilíbrio: $Q_{1}$, ausência das duas bactérias (bactérias lácticas e Listeria) no alimento; $Q_{2}$, apenas bactéria láctica presente; e $Q_{3}$, "coexistência" das duas bactérias.

Através da análise do modelo foi possível obter informações sobre o comportamento das soluções, e, também, determinar uma possível ação do ácido láctico e da bacteriocina produzidos pela bactéria láctica, para o controle da Listeria no 
alimento. O sistema fornece, além do ponto de equilíbrio trivial $\left(Q_{1}\right)$, dois outros pontos de equilíbrio não triviais. Um dos pontos de equilíbrio não trivial é sempre instável $\left(Q_{3}\right)$, e o outro $\left(Q_{2}\right)$, pode ser estável, desde que a interação entre o ácido láctico e a bacteriocina, produzidos pela bactéria láctica, com o patógeno, ocorra fortemente em relação a valores limiares. Em outras palavras, quando ocorre ação destes metabólitos inibidores sobre a Listeria de forma eficiente, é possível inibir o crescimento ou até mesmo diminuir a contaminação até que haja a extinção da Listeria. Esses valores limiares mostram que, quando a bacteriocina é bastante reativa $\left(\delta_{2}>\delta_{2}^{t h}\right)$, é possível controlar o crescimento desse patógeno, independentemente da interação da Listeria com o ácido láctico. Esse resultado dá apoio ao uso de bacteriocina purificada na conservação de alimentos por parte da indústria de alimentos, que tem-se mostrado preocupada devido à alta taxa de mortalidade aos consumidores e pelos prejuízos que a contaminação do alimento pela Listeria pode acarretar ao produtor.

Abstract In this paper we develop a mathematical model to describe the interaction between lactic acid bacteria producing bacteriocin and the Listeria monocytogenes in the food. The steady state and dynamical trajectories analyses of the model, which was structured as a system of nonlinear ordinary differential equations, permit us to study the possible use of lactic bacteria in order to reduce and to inhibit the development of Listeria in the food.

\section{Referências}

[1] R. Bromberg, I. Moreno, R.R. Delboni, H.C. Cintra, Características da bacteriocina produzida por Lactococcus lactis ssp. hordniae CTC 484 e seu efeito sobre Listeria monocytogenes em carne bovina, Ciênc. Tecnol. Aliment., 26, No. 1 (2006), 135-144.

[2] E. Caplice, G.F. Fitzgerald, Food fermentations: role of microorganisms in food producton and preservation, International Journal of Food Microbiology, 50 (1999), 131-149.

[3] M. Desmazeaud, Bacteriocins of lactic acid bacteria (LAB) and their interest to improve the higienic quality of products, Cerela, 8 (1997), 38-43.

[4] P. Glendining, "Stability, Instability and Chaos: an introduction to the theory of nonlinear differential equations", Cambridge University Press, Cambridge, 1994.

[5] C.B. Lewus, T.J. Montville, Detection of bacteriocins produced by lactic acid bacteria, Journal Microbiology Methods, 13 (1991), 145-150.

[6] P.M. Muriana, Bacteriocins for control of Listeria spp in food, Journal of Food Protection, Supplement (1996), 54-63.

[7] J.M. Rodriguez et al., Inhibition of Listeria monocytogenes by Lactobacillus sake strains of meat origin, Meat Science, 38 (1994), 17-26. 